\title{
Bilateral nail gun traumatic brain injury presents as intentional overdose: A case report
}

\author{
Judith Alain, MD, MSc*; Pascal Lavergne, $\mathrm{MD}^{\dagger}$; Maude St-Onge, MD, $\mathrm{PhD}^{\ddagger \S}$; Myreille $\mathrm{D}^{\prime}$ Astous, MD, \\ $\mathrm{PhD}^{\dagger}$; Stéphane Côté, $\mathrm{MD}, \mathrm{PhD}^{*}$
}

\begin{abstract}
This report describes a rare but life-threatening case of a suicide attempt initially considered as intentional overdose at the emergency department. Persistent altered mental status, despite normal toxicology investigations, led the attending team to order a head computed tomography scan, which revealed a bilateral penetrating nail gun injury with a right temporal hematoma for which a decompressive craniectomy was performed. Although voluntary intoxication is the most frequent form of suicide attempt, emergency physicians must be alert and maintain a broad differential diagnosis. Although rare, penetrating head injuries have increased in recent decades. As neurological symptoms can be minimal and penetration wounds small, this type of injury could potentially be overlooked.
\end{abstract}

\section{RÉSUMÉ}

Nous présentons un cas de tentative de suicide évalué au département d'urgence avec les manifestations cliniques initiales d'une intoxication volontaire. L'altération de l'état de conscience persistante en dépit d'un bilan toxicologique normal a conduit l'équipe traitante à effectuer un TDM cérébral. Cet examen a démontré la présence de clous intracrâniens bilatéraux ainsi qu'un hématome temporal droit pour lequel une craniectomie décompressive a été réalisée. Les intoxications volontaires demeurent les tentatives de suicide les plus fréquentes. Néanmoins les urgentologues doivent demeurer vigilants et conserver un diagnostic differentiel élargi. La possibilité d'un trauma cérébral pénétrant demeure rare, mais en augmentation depuis les dernières décennies. Les symptômes neurologiques variables associés à ce type de trauma et les lésions cutanées minimes ou dissimulées ont le potentiel d'être manqués à l'urgence.

Keywords: Nail gun, craniocerebral injury, suicide, penetrating brain injury, self-inflicted injury, penetrating cranial trauma, overdose

\section{INTRODUCTION}

Suicide attempts account for a significant number of emergency department (ED) visits and represent a major cause of mortality and morbidity. ${ }^{1,2,15}$ Poisoning is the second most common method of completed suicide , $^{3,415}$ and the most common method among hospitalizations related to suicide attempts $(83 \%)$ in Canada. ${ }^{2}$ Consequently, emergency physicians managing patients who present with altered mental status in the context of a suicide attempt frequently encounter self-poisoning. Our objective in presenting this unique case is to demonstrate that penetrating nail gun brain injury, although rare, represents a highly morbid suicide method that can be initially unrecognized as such in the ED. A cautious approach is necessary in the context of limited patient history and altered mental status, because this common presentation may point to a rare diagnosis that can be overlooked.

\section{CASE REPORT}

This is the case of a single, 50-year-old man. Police and paramedics found the patient in his apartment after being alerted by his employer, who had not seen him for 2 days. The patient was lying on the floor, drowsy but arousable. Hanging materials, suicide letter, empty beers, and construction gear were found at the scene. No medication or signs of violence were observed. Upon arrival at the ED, the patient had an altered mental status, a Glasgow Coma Scale (GCS) score of 13 (E3, V4, M6) without any focal neurological deficit and normal vital signs, including a heart rate of 65 beats per minute, a respiratory rate of 15 breaths per minute, a blood pressure reading of 130/ $84 \mathrm{~mm} \mathrm{Hg}$, 95\% oxygen saturation, and a normal temperature and blood glucose level.

In the ED, the patient denied any medication, drug, or alcohol ingestion. No seizure activity was observed, although urinary incontinence was noted without tongue-biting. He had a saturation level of $100 \%$ with

From the *Department of Emergency Medicine; †Department of Surgery, CHU de Québec - Université Laval, Quebec City, QC; $¥$ Trauma Emergency - Critical Care Medicine, CHU de Quebec Research Centre, Quebec City, QC; and the §Quebec Poison Control Centre, Quebec City, QC.

Correspondence to: Dr. Stéphane Côté, CHU de Québec-Centre hospitalier de I'Université Laval (CHUL), 2705 Laurier Blvd., Québec City, QC G1V 4G2; Email: Sctoe@hotmail.com

(C) Canadian Association of Emergency Physicians

CJEM 2018;20(5):788-791

DOI $10.1017 /$ cem.2017.5 
$2 \mathrm{~L}$ of oxygen and a respiratory rate of 13 breaths per minute. It was difficult to perform a neurological exam because he was uncooperative, but his motor functions were grossly intact. Deep tendon reflexes were symmetric without clonus. Cranial nerves otherwise appeared to be intact, with reactive pupils at $3 \mathrm{~mm}$. No evidence of meningismus was found, and the scalp was intact. The rest of the physical examination was normal. No family was available, and no past medical history or prescriptions were found in the electronic medical record. This undifferentiated presentation was not consistent with a specific toxidrome, although selfpoisoning was suspected based on the circumstances reported by the paramedics. Toxicology investigations were requested.

Ten minutes after the initial assessment, the patient's neurological condition deteriorated to $6(\mathrm{E} 1, \mathrm{~V} 1, \mathrm{M} 4)$ on the GCS. The patient's stuporous condition and the miosis led the clinician to consider an opioid overdose. Administration of $0.2 \mathrm{mg}$ of intravenous naloxone was associated with an improvement of the GCS score up to 13 (E3, V5, M5) within 1 minute. However, the patient did not present a tight miosis (3-mm pupil size) and kept a respiratory rate of 16 breaths per minute. Therefore, the medical team did not repeat naloxone administration until further investigations specified the underlying cause.

Thirty minutes later, partial laboratory results were unremarkable other than leukocytosis of $16.9 \times 10^{9} / \mathrm{L}$. The capillary blood gas showed a $\mathrm{pH}$ of 7.45 , a $\mathrm{pCO}_{2}$ of $41 \mathrm{mmol} / \mathrm{L}$ and bicarbonate of $28 \mathrm{mmol} / \mathrm{L}$. Renal function, electrolytes, anion gap, and osmolar gap were normal. The electrocardiogram showed a sinus rhythm without tricyclic toxicity signs with a QRS of $104 \mathrm{~ms}$ and a normal QT. Additional toxicological tests were awaited. The levels of ethanol, acetaminophen, aspirin, lithium, valproic acid and carboxyhemoglobin were undetectable. Thyroid-stimulating hormone, international normalized ratio, hepatic enzymes, and chest and abdominal X-rays were normal.

After receiving the complete investigation results, the bedside physician reconsidered his diagnosis. A repeat physical examination showed no other findings except for abnormal rigidity in his left upper extremity, with possible slight cogwheel rigidity. This new focal neurological deficit led the physician to order a head computed tomography (CT) scan to rule out a possible intracranial abnormality.

Two and a half hours after the patient's first assessment, the imaging showed two $8.0-\mathrm{cm}$ nails that had entered the skull bilaterally in each temporal region, crossing the midline at the level of the thalami, with mass effect (Figure 1). An associated right temporal intraparenchymal hematoma measuring $4.92 \mathrm{~cm} \times 2.67$ $\mathrm{cm}$ and a subarachnoid hemorrhage in the Sylvian fissure were present. The patient's temporal regions were re-evaluated for entry wounds. When looked for, the two small nail heads were visible bilaterally, deeply hidden underneath the patient's hair, without any external bleeding.

The patient was promptly transferred to a specialized neurosurgery centre. Antitetanus immunoglobulin, prophylactic anticonvulsants, and antibiotics (intravenous ceftriaxone $2 \mathrm{~g}$ and vancomycin $1 \mathrm{~g}$ ) were given.

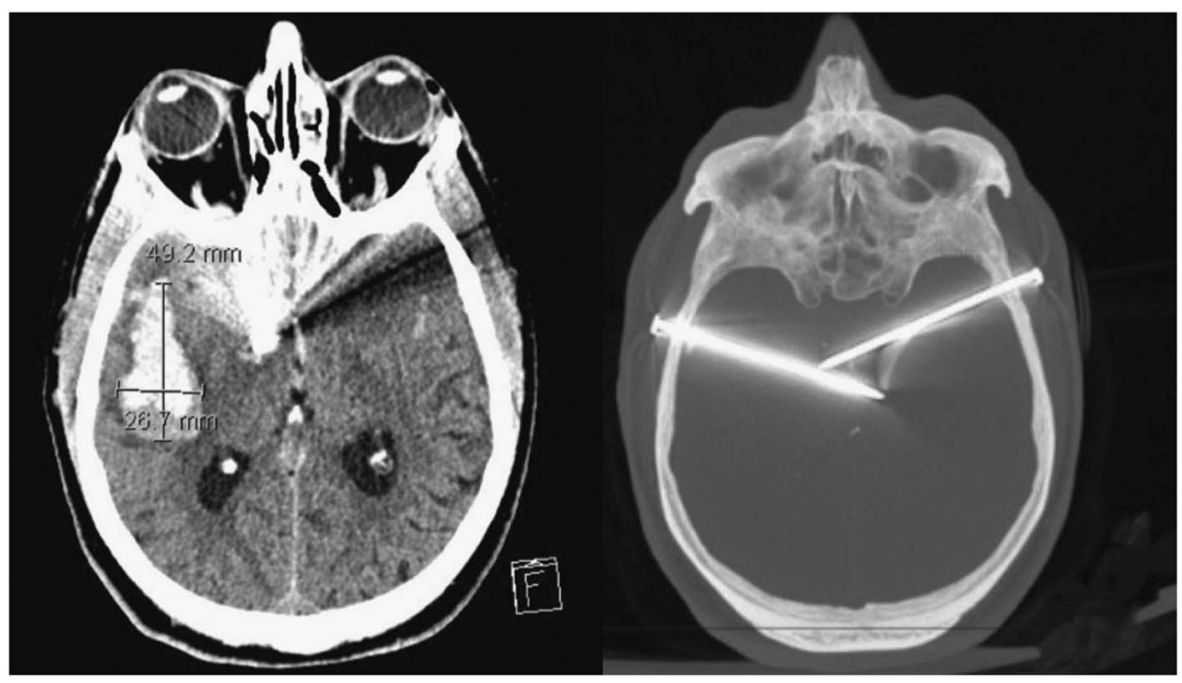

Figure 1. Initial CT scan showing bilateral intracerebral trauma with a right-side temporal hematoma. 
On initial evaluation by the neurosurgical team, the patient had a decreased level of consciousness (GSC 10: $\mathrm{E} 2, \mathrm{~V} 3, \mathrm{M} 5$ ), and a surgical indication for decompressive craniectomy was determined. The surgery had three goals: remove foreign bodies, drain the right temporal hematoma, and prevent increased intracranial pressure. The hematoma was drained and an external ventricular drain inserted. There was no bleeding after the removal of both nails, but the angiography team was on standby in case of any uncontrollable bleeding. Closing included an expansion duraplasty, leaving the bone flap out.

After surgery, the patient remained intubated for 7 days. He did not develop intracranial hypertension or new major hematoma upon removal of the nails. In this context, the external ventricular drain was weaned off after 4 days. A follow-up CT angiography on postoperative days 2, 10, 21, and 49 showed no pseudoaneurysm or arterial dissection. His bone flap was replaced 1 month after the initial trauma without complications. Prophylactic antibiotic therapy was continued for 7 days, in accordance with the infectious disease specialist's recommendations. Prophylactic anticonvulsant therapy was continued for 6 months due to the higher risk of seizures with penetrating trauma.

The patient's clinical condition improved gradually over 2 weeks. When discharged from the intensive care unit, he had persistent cognitive and functional deficits, which required rehabilitation. After a 2-month hospital stay, the patient was transferred to a long-term rehabilitation facility. The patient remained with significant residual cognitive deficits requiring long-term care and assistance from caregivers for daily living activities, scoring 4 on the modified Rankin Scale.

\section{DISCUSSION}

Penetrating craniocerebral injuries caused by pneumatic nail guns are uncommon but well-characterized entities that have increased in frequency in recent decades. ${ }^{5-9}$ The literature suggests that the majority of nail gun brain injuries are found to be intentional and selfinflicted. ${ }^{8-13}$ Initial presentation varies considerably among injured patients - from sudden death to minimal neurological symptoms-depending on nail trajectory and on which cerebral structures have been injured. ${ }^{14}$ This variable presentation combined with an incomplete history and lack of obvious physical findings may pose a diagnostic challenge in the ED.
The literature reported a case of a man who consulted at the ED for a suicide attempt by shooting himself with a nail gun. He was asymptomatic despite having a $6.5-\mathrm{cm}$ nail in his right temporal lobe. His story was found implausible because there was no apparent wound or neurological symptoms. He was discharged from the ED. Four days later, the patient was brought back to the ED with a GCS of 14 and left-sided hemiparesis after he shot himself again with two longer nails. ${ }^{14}$ This clinical case shows that signs and symptoms can be subtle, despite a significant penetrating brain injury.

In this case report, the limited local injury on the scalp hiding underneath the patient's hair and the absence of bleeding or coagulated blood near the nail entry wound made the diagnosis of penetrating brain injury very unlikely. Mental status fluctuation was due to the penetrating trauma and hematoma progression. The naloxone response was retrospectively judged to be a coincidence.

This unusual case report underlines the importance of reconsidering the initial differential diagnosis when a case is not evolving as expected. After the first examination, the negative investigation combined with the persistent altered level of consciousness without respiratory depression invalidated the working hypothesis. The focal neurological deficit found on the patient's re-examination led to the ultimate diagnosis 2 and a half hours following the patient's arrival at the ED. The willingness to reconsider diagnosis was essential in this case, specifically considering the incomplete history.

In retrospect, the paramedics had noted the presence of a compressed air nail gun at the patient's apartment. This information was not specifically emphasized upon arrival at the ED because no one thought that this could be key information leading to the patient's diagnosis. An earlier diagnosis could have been made if the medical team would have been aware of this lethal suicide method with highly variable neurological presentation depending on nail trajectory. Air compressor use may also result in carbon monoxide poisoning, which has to be excluded when managing altered mental status.

In this case, the patient was not intubated prior to his transfer to the neurosurgical centre. This decision was made based on the short distance of the transfer and the neurological team's desire to assess the neurological status of the patient. However, considering the 
penetrating brain injury with the intraparenchymal hematoma, a longer transfer time or reduced level of consciousness at the initial facility would have required that the patient's airway be secured for transfer.

The neurosurgical management of this case is also of interest because of the highly unusual presentation of bilateral trauma. Follow-up also included prevention of infection and seizures.

\section{CONCLUSION}

Emergency physicians must approach undifferentiated clinical presentations with an open mind and a broad differential diagnosis. A high index of suspicion for structural brain lesions should be maintained when the cause of an altered level of consciousness is unclear. This case report is a good reminder that a common presentation may point to a rare diagnosis that can be easily overlooked. This nail gun suicide attempt report exposes a unique presentation that can be mistaken for intentional drug intoxication. Emergency physicians must be aware that this form of suicide attempt is rare but increasing in frequency. Penetrating nail gun brain injuries are mostly self-inflicted and can be missed if not specifically looked for.

The patient and his substitute decision-makers consented to the publication of this case report.

Competing interests: None declared.

\section{REFERENCES}

1. Dubovsky SL, Dubovsky AN. Mood disorders and the outcome of suicidal thoughts and attempts. Crit Care Clin 2008;24(4):857-74, ix.
2. Langlois S, Morrison P. Suicide deaths and suicide attempts. Health Rep 2002;13(2):9-22.

3. Navaneelan T. Suicide rates: An overview. Catalogue No. 82-624-X. Ottawa: Statistics Canada; 2015.

4. Pajonk FG, Gruenberg KA, Moecke H, et al. Suicides and suicide attempts in emergency medicine. Crisis 2002; 23(2):68-73.

5. Birkhead GS, Galvin VG, Meehan PJ, et al. The emergency department in surveillance of attempted suicide: findings and methodologic considerations. Public Health Rep 1993; 108(3):323-31.

6. Yuh SJ, Alaqeel A. Ten self-inflicted intracranial penetrating nail gun injuries. Neurosciences (Riyadb) 2015;20(3):267-70.

7. Luo W, Liu H, Hao S, et al. Penetrating brain injury caused by nail guns: two case reports and a review of the literature. Brain Inj 2012;26(13-14):1756-62.

8. Elisei S, Verdolini N, Anastasi S. Suicidal attempts among emergency department patients: one-year of clinical experience. Psychiatr Danub 2012;24(Suppl 1):S140-2.

9. Testerman GM, Dacks LM. Multiple self-inflicted nail gun head injury. South Med 7 2007;100(6):608-10.

10. Litvack ZN, Hunt MA, Weinstein JS, et al. Self-inflicted nail-gun injury with 12 cranial penetrations and associated cerebral trauma. Case report and review of the literature. 7 Neurosurg 2006;104(5):828-34.

11. Kaufman KR, Schineller TM, Tobia A, et al. Hypersexuality after self-inflicted nail gun penetrating traumatic brain injury and neurosurgery: case analysis with literature review. Ann Clin Psychiatry 2014;26(4):e1-4.

12. Aghabiklooei A, Molahoseini R, Khajoo A, et al. Multiple nails in the brain: an unusual suicidal attempt. Am 7 Forensic Med Pathol 2012;33(1):88-9.

13. Lee CS, Park KH. Six nails in the head: multiple pneumatic nail gun head injury. Br 7 Neurosurg 2010;24(4):493-4.

14. Zazpe I, Vazquez A, Beaumont C, et al. Multiple penetrating brain injuries caused by a nail gun: a case report. Neurocirugia (Astur) 2006;17(6):544-9.

15. Springborg JB, Eskesen V, Olsen NV, et al. Cranio-cerebral injuries caused by nail guns: report on two cases, review of the literature and treatment algorithm. 7 Trauma 2007; 63(2):E59-64. 